\title{
EN MEMORIA DE GYÖRGY RÁNKI
}

IVÁN T. BEREND

Resulta duro escribir de Ránki en pasado. Su dinámica personalidad, su incansable diligencia y capacidad para comprimir dos días de trabajo en cuarenta y ocho horas, hace que sea difícil pensar que Ránki murió en febrero de 1988. Sus amigos y colegas, estudiantes y lectores aún no han advertido su desaparición, ya que su influencia y continua actividad están todavía entre nosotros, y seguimos preguntándonos qué nos habría dicho ante este o aquel asunto.

No pudimos dedicar a nuestros amigos el último libro que hemos escrito juntos, sobre la historia económica de Europa en el siglo xIx, y que sintetiza veinticinco años de trabajo, puesto que se publicó pocas semanas antes de su muerte. Y otro libro, que escribió él solo, se ha editado recientemente, a los tres meses de su fallecimiento. Su último gran proyecto, un voluminoso estudio de la historia de la economía mundial durante la Segunda Guerra Mundial, también pronto va a ser publicado. Nada más simbólico de su persona y de su carácter que ver cómo incluso después de su muerte sigue publicando.

Es difícil para mí escribir acerca de su obra. Durante más de cuatro décadas hemos trabajado juntos; comenzamos en nuestros años de universidad y hemos continuado haciéndolo hasta la misma fecha de su muerte; por ello yo no puedo hacer una evaluación objetiva de su contribución a la historia económica. En veinte monografías que hemos escrito juntos, sobre la historia de la economía de Hungría y de Europa Central y del Este, hemos intentado realizar un estudio comparado de historia económica, y el interés despertado por nuestro trabajo se manifiesta en las ediciones que se han hecho en Estados Unidos, Gran Bretaña, Japón y Alemania. Con su trabajo en solitario también ha hecho importantes contribuciones a la historia internacional durante y después de la Segunda Guerra Mundial.

Pero permítaseme ahora referirme a algunos recuerdos comunes: vienen a mi memoria los años de universidad y la emoción que experimentábamos investigando en los archivos durante innumerables días de verano; recuerdo las experiencias vividas en la primera y en las sucesivas reuniones internacionales 
donde presentábamos nuestras investigaciones, y la felicidad que nos ha proporcionado escribir más de diez mil páginas juntos. Mucha gente, en muchas ocasiones, nos ha preguntado cómo podíamos escribir juntos. Nos resultaba difícil explicarlo: nuestro primer volumen lo llevamos a cabo discutiendo cada frase, cada párrafo; nuestros últimos libros los hemos hecho de la misma forma, aunque nos hayamos encontrado separados por largas distancias. Sólo es posible comprender nuestra compenetración si se tiene en cuenta la unidad y armonía que, con el paso del tiempo, habían adquirido nuestras ideas y pensamientos.

Durante su vida nunca tuve la oportunidad de decirle en cuánto apreciaba su talento. Quizá porque nunca nos gustaba alabarnos cara a cara, y preferíamos la ironía y la discusión. Nunca pude decirle cuánto admiraba su inigualable dominio de los idiomas y lo sorprendido que me dejaba con su excepcional erudición y su habilidad para mantenerse al día en una gran variedad de materias. Más aún, su capacidad intelectual se complementaba con una extraordinaria competencia para la organización. Siempre que viajábamos juntos y vagábamos por una ciudad desconocida podía confiarme totalmente a su dirección. Yo no necesitaba ni una agenda ni un mapa; de hecho, no necesitaba preocuparme por nada.

Ránki creó un Instituto de investigación, formó un Departamento universitario y organizó continuas conferencias internacionales, siempre cuidando los detalles, tanto financieros como profesionales. Fue a un mismo tiempo director del Instituto de Historia de la Academia de Ciencias de Hungría, presidente del Departamento de Historia y Filosofía de la Academia, titular de la Cátedra húngara de la Universidad de Indiana en Bloomington y vicepresidente primero de la Asociación de Historia Internacional. Además, era miembro destacado de numerosos comités y asociaciones. En todos estos puestos siempre quiso contribuir con una presencia activa; su labor constante y desinteresada resultó para todos provechosa y valiosa, por lo que será recordado durante mucho tiempo. Debo decir, aunque pueda resultar lugar común, que Ránki es ciertamente irremplazable.

Gyuri ya no está entre nosotros. Pero yo, como siempre he hecho, sigo hablando a menudo con él. Sus estudiantes llevan la marca de su personalidad en sus enseñanzas y en su carácter. Sigue presente en las estanterías de las bibliotecas y sus libros siguen siendo leídos en todo el mundo. Mucha gente, en muchos lugares, lamenta su muerte y echa en falta su persona y su trabajo. Su muerte es una gran pérdida para todos y una gran pena para nosotros.

(Traducción de Pablo Martín AcEÑa.) 